\title{
SUSTAINABLE ENERGY DEVELOPMENT
}

Vera Lisitsa

Sumy State University, Sumy, Ukraine

Recent reports released by the Intergovernmental Panel on Climate Change (IPCC) in 2007 state unequivocally that the world is warming and that human activity - rather than just natural variations - has contributed to current levels of warming. The reports provide a comprehensive analysis of how climate change is affecting natural and human systems.

The findings underscore that fact that climate change is a key development concern. The people most at risk from climate change live in countries that have contributed the least to the atmospheric build up of carbon dioxide and other greenhouse gases linked to the recent warming of the planet.

Further, those most affected are also least able to cope, making it an issue of inequality and insecurity.

The inefficient and polluting energy systems in Ukraine are glaring economic and environmental problems interwoven with promising opportunities for reducing global greenhouse gas emissions. Ukraine economy suffered from the low productivity and living standards associated with inefficient energy use long before central planning came to an end.

Scientists have a prognosis:

- that world energy demand will grow by two-thirds in the next 30 years;

- that fossil fuels will continue to dominate the energy mix;

- that nearly two-thirds of the growth in energy demand will arise in developing countries;

- that financing the required new energy infrastructure is a huge challenge, depending largely on the framework conditions created by governments;

- that international energy trade will expand dramatically;

- that natural gas demand growth will outpace that of any other fossil fuel, but will itself be outpaced by demand growth for renewables;

- that transport will dominate the growth in oil use;

- that electricity use will grow faster than any other energy end-use;

- that the proportion of the world's population without access to electricity will fall by a third; or, conversely, that 1.4 billion people will still lack access to electricity in 2030;

The production, transformation and consumption of energy give rise to environmental problems, such as the emission of $\mathrm{CO}_{2}$ and local pollutants like $\mathrm{SO}_{2}$, which are of growing concern worldwide.

IEA Ministers recognise that current energy trends are not sustainable and that a better balance must be found between the three Es - energy security, economic development and protection of the environment.

Energy is part of many environmental problems, including climate change, and must be part of the solution. The IEA has been engaged for more than a decade on designing cost-effective approaches to reduce $\mathrm{CO}_{2}$ emissions, from the international policy architecture (including trading mechanisms) to energy efficiency policy and the promotion of clean technologies.

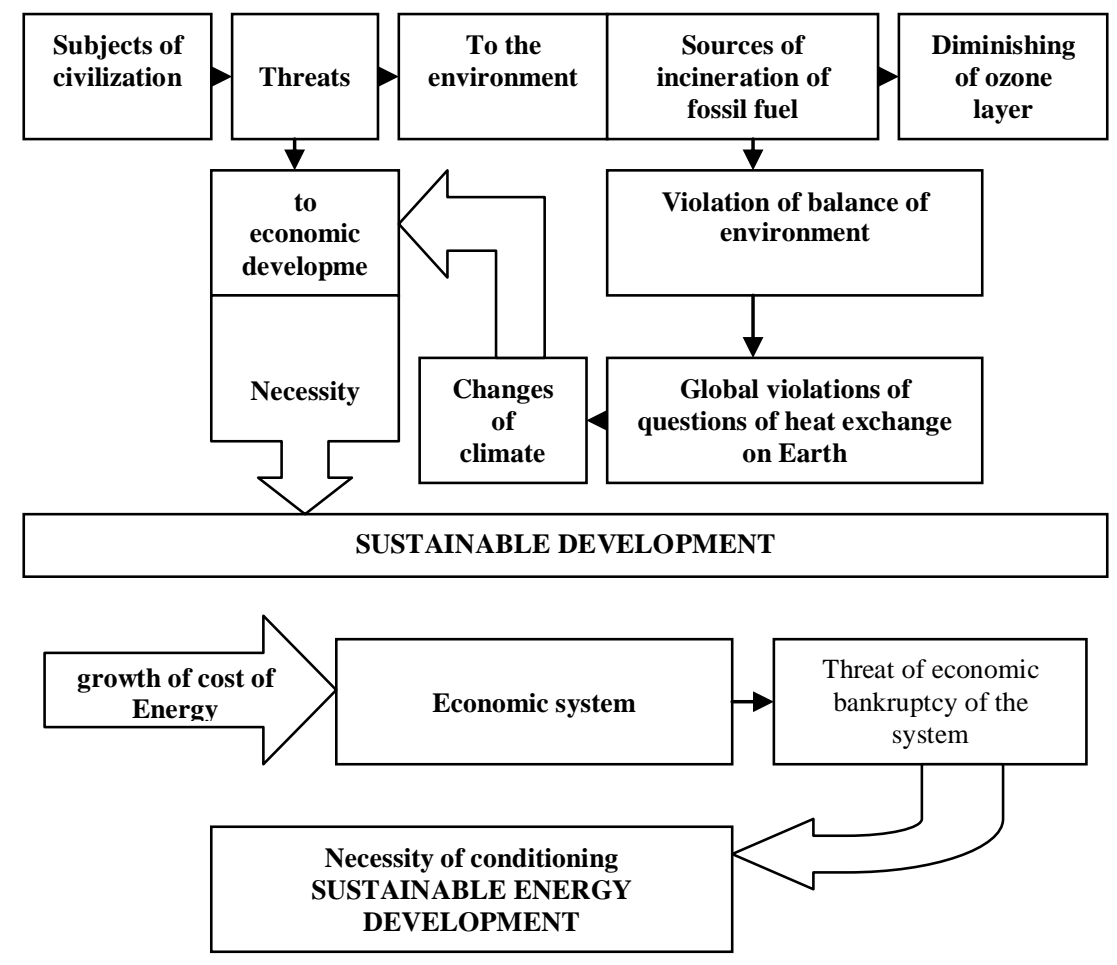


Ukraine must be active in initiatives within the UN system to promote sustainable development and follow up the Johannesburg Plan of Implementation and the UN's Millennium.

In the future a major scientist's activity must main continuing coordination of all of the interested parties to produce a major interagency publication and development Energy Indicators for Sustainable Development: Guidelines and Methodologies.

UN Energy is designed to better connect energy activities throughout the UN system, to continuously improve efficiency and mutual support. 